\title{
Effects of Process Conditions on Hydrogen Production of Fe Complexes Catalyst in Noble-Metal-Free System
}

\author{
Chuang ZHANG ${ }^{1, a}$, Da-TianFU ${ }^{2, b}$, Xiu-Lan CAI ${ }^{1, \mathrm{c}, *}$ \\ ${ }^{1}$ Guangdong Pharmaceutical University, China \\ ${ }^{2}$ Hainan Cancer Hospital, China \\ azhangchuang910516@outlook.com, budatian123@126.com, 'caixiulan78@126.com \\ ${ }^{*}$ Corresponding author
}

Keywords: Fe complexes; Process conditions; Hydrogen

\begin{abstract}
In this paper, Fe thiolate complexes $\mathrm{Fe}(\mathrm{phen})(\mathrm{pyS})_{2}(\mathrm{M})$ were synthesized, the properties of complexes were characterized by ${ }^{1} \mathrm{H}-\mathrm{NMR}$ and MS. The effects of reaction conditions on catalytic performance of catalyst $\mathrm{M}$ had been studied. The results of catalytic performance indicated that the optimal reaction conditions were that catalyst concentration was $5.00 \%$, triethylamine was the suitable electron donor and the optimal riethylamine content was $5.00 \%$. The maximum hydrogen yield was $156.1 \mu \mathrm{mol} / \mathrm{h}$ after reacted for 15 hours and the life of catalyst $\mathrm{M}$ was $41 \mathrm{~h}$ under the optimal reaction conditions.
\end{abstract}

\section{Introduction}

In recent years, more and more people realized that it is particularly urgent to find new energy sources because of the hostile environment. A system of photo generated hydrogen were reported and most of them were about molecular photo catalysis [1-5].

Recently, $\mathrm{Co}(\mathrm{dmgh})_{2}\left(\mathrm{H}_{2} \mathrm{O}\right)_{2}$, a homogeneous system for $\mathrm{H}_{2}$ generationmade up of triethanolamine (TEOA), $\left[\mathrm{Ru}(\mathrm{bpy})_{3}\right]^{2+}$ (bpy=2,2'-bipyridine) in DMP solution with $\mathrm{pH}$ value 8.8 . The turnover number (TON) was 38irradiated by the visible light[6].[Co(bpy $\left.)_{3}\right] \mathrm{Cl}_{2}$, Rose Bengal and triethylamine(TEA) were used as catalyst, photosensitizer and sacrificial electron donor respectively. The corresponding $\mathrm{H}_{2}$ yield of 2076 TON was reported[7].

In this paper, a new noble-metal-free complex $\mathrm{Fe}(\mathrm{phen})(\mathrm{pyS})_{2}(\mathrm{M})$ was synthesized. The properties of complexes were characterized by ${ }^{1} \mathrm{H}-\mathrm{NMR}$ and MS and the effects of reaction conditions on catalytic performance had been researched.

\section{Experimental}

\subsection{Reagents and Instruments}

All reactions were carried out under $\mathrm{N}_{2}$ atmosphere with standard Schlenk techniques. Solvents were dried with $4 \AA$ molecular sieves and distilled prior to be used according to the standard methods. Pyridine-2-thiol (pySH), 1,10-phenanthroline hydrate, sodium metal, fluoresce in (Fl) and triethylamine (TEA) were purchased from Aldrich and used without further purification.

\subsection{Synthesis of Fe (phen)(pyS) 2}

$\mathrm{Fe}(\mathrm{bpy})(\mathrm{pyS})_{2}(\mathrm{M})$ was synthesized as Fig. 1. The solution of 1, 10-phenanthroline (1.3 g, $\left.6.4 \mathrm{mmol}\right)$ in $10 \mathrm{~mL}$ of acetonitrile was added slowly to the solution containing $\mathrm{FeCl}_{3}\left(\mathrm{H}_{2} \mathrm{O}\right)_{6}(1.7 \mathrm{~g}, 6.4 \mathrm{mmol})$ in $80 \mathrm{~mL}$ of acetonitrile over $30 \mathrm{~min}$. The color of the above solution changed from light violet to dark violet. Then a solution containing py SH (1.42 g, $12.9 \mathrm{mmol})$ and TEA (2.2 mL, $16.0 \mathrm{mmol})$ in $30 \mathrm{~mL}$ of acetonitrile was added to above mixed solution slowly over $1 \mathrm{~h}$. The solution turned 
brown, and a brown precipitate formed after stirring for another $8 \mathrm{~h}$. The product (M) was collected by suction filtration. The products were stored under atmosphere without protection from water and oxygen.

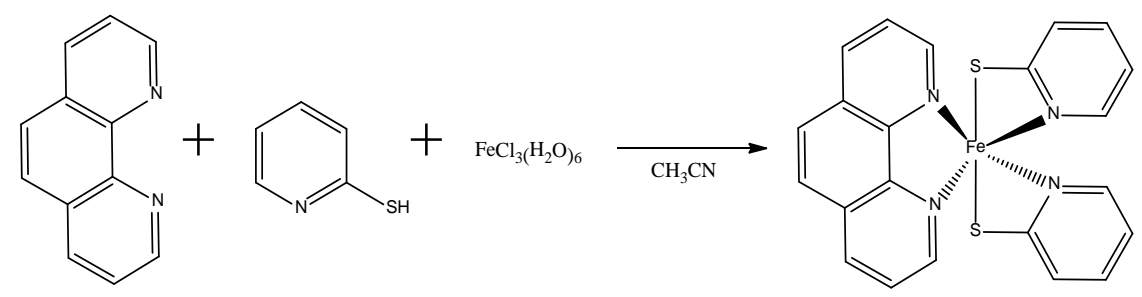

Fig. 1 The synthetic routes of $\mathrm{M}$

The yield of M was $1.2 \mathrm{~g}(50 \%) .{ }^{1} \mathrm{H}-\mathrm{NMR}\left(\mathrm{CDCl}_{3}, 20{ }^{\circ} \mathrm{C}\right): \delta 8.73,8.25,7.6 \mathrm{ppm}$. ESI MS: $\mathrm{m} / \mathrm{z}$ 456.02 (expected), 456.02 (found). Elem. Anal. Calculated: C, 57.90; H, 3.53; N, 12.28; Found: C, 57.91; H, 3.52; N, 12.2.

\section{$2.3{ }^{1} \mathrm{H}-\mathrm{NMR}$ Spectra}

${ }^{1} \mathrm{H}-\mathrm{NMR}$ spectra were collected on Varian INOVA 400NMR spectrometer.

\subsection{Mass Spectra}

Mass spectra were performed by electrospray ionization (ESI) on HP 1100 MSD instrument.

\subsection{Evaluation of Performance of Photocatalyst or Hydrogen Production}

The $0.04 \mathrm{mM}$ photocatalysts was placed in the solfution containing ethanol/ $\mathrm{H}_{2} \mathrm{O}\left(1: 1_{\mathrm{v} / \mathrm{v}} 120 \mathrm{~mL}\right)$, $2.0 \mathrm{mM} \mathrm{Fl}$ and TEA (5\% v/v). The above solution was place in an inner irradiation quartz cell (250 $\mathrm{mL}$ ) and protected from light before use. The $\mathrm{pH}$ values of the solutions were measured with $\mathrm{pH}$ meter and adjusted to 11.6 by adding $\mathrm{HCl}$ or $\mathrm{NaOH}$. The photocatalysis system were kept at $25{ }^{\circ} \mathrm{C}$. The cell were irradiated with a $500 \mathrm{~W}$ Xe lamp and the produces were analyzed with an on-line TCD gas chromatograph (GC-9800). During the irradiation process, $0.5 \mathrm{~mL}$ methane was used as the internal standard gas, and the amount of hydrogen was calculated according to the amount of methane.

\section{Results and Discussion}

The results of previous studies indicated that the main influencing factors on performance of photocatalytic system for hydrogen production were catalyst concentration, electron donor and its content. In this paper, the effects of catalyst concentration, electron donor and its content on the performance of catalyst $\mathrm{M}$ were investigated and the optimum conditions for hydrogen production were determined.

\subsection{The Effects of Catalyst Concentrations on the Performance of Catalyst $M$ for Hydrogen Production}

In this paper, the effects of catalyst concentrations $(1.25 \%, 2.50 \%, 3.75 \%$ and $5.00 \%)$ on photocatalytic performances were investigated and the experimental results were shown in Fig. 2. 


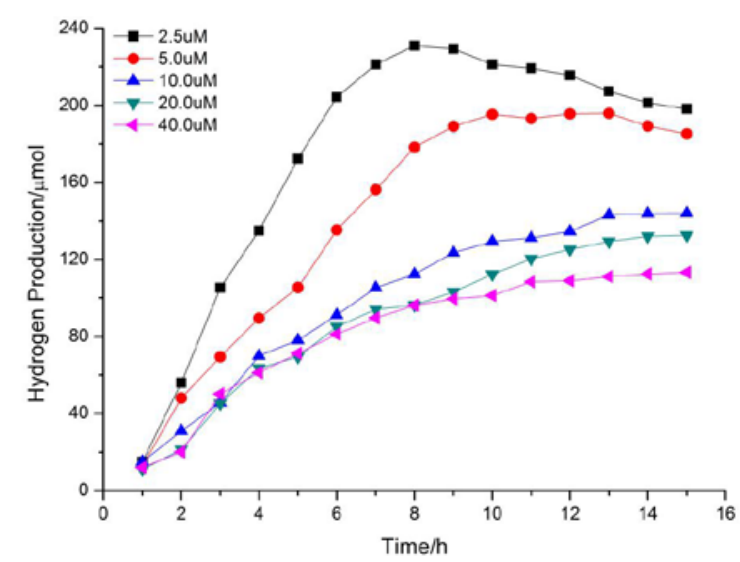

Fig. 2 Effects of catalyst concentrations on the performance of catalyst $\mathrm{M}$ for hydrogen production

Fig. 2 showed that with the increasing of catalyst concentration, hydrogen production was gradually increased. When the concentration of catalyst $\mathrm{M}$ was $1.25 \%$, hydrogen production reached $115.9 \mu \mathrm{mol}$ after reacted for $15 \mathrm{~h}$. When the concentration of catalyst $\mathrm{M}$ increased to $5.00 \%$, hydrogen production $229.4 \mathrm{~mol}$. Therefore, the optimum catalyst concentration was $5.00 \%$.

\subsection{The Effects of Electron Donor on Performance of Catalyst $M$ for Hydrogen Production}

In this photocatalysis system, concentration of catalyst $M$ was $5.00 \%$, fluorescein concentration was $2.0 \mathrm{mM}$ ), volume ratio of ethanol/water was $1: 1$ and $\mathrm{pH}$ value was 11.6 . In the process of reaction, light intensity, stirring speed and temperature remained constant for $15 \mathrm{~h}$. The effects of two electron donor triethylamine and triethanolamine (two electron donor content was 5\%) on catalytic performance were studied and the experimental results were showed in Fig. 3.

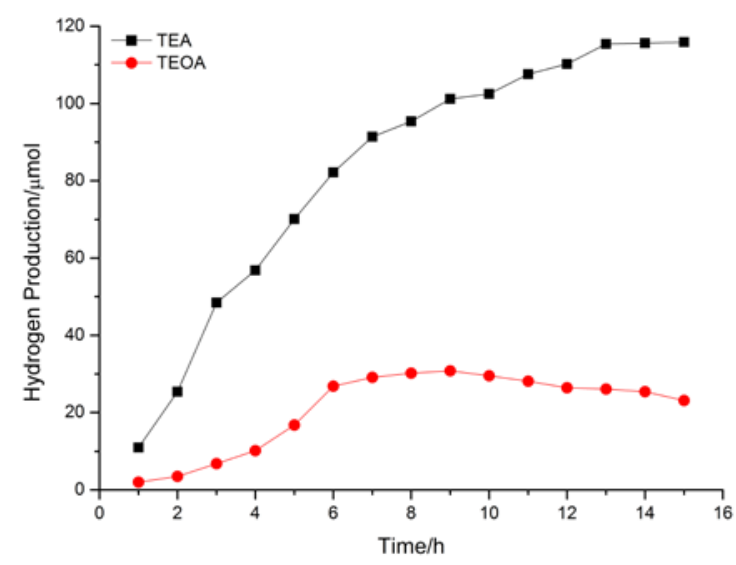

Fig. 3 Effects of electron donor on performance of catalyst $M$ for hydrogen production

The results of Fig. 3 indicated that compared to triethanolamine as electron donor, catalytic performance was significantly higher when electron donor was triethylamine and the hydrogen production reached $115.9 \mu \mathrm{mol}$ after reacted for $15 \mathrm{~h}$. Therefore, in this reaction system, triethylamine was the suitable electron donor.

3.2 The Effects of Electron Donor Concentrations on the Performance of Catalyst $M$ for 


\section{Hydrogen Production}

In addition, the effects of electron donor concentrations(1.25\%, 2.50\%, 3.75\%, 5\%) on the catalytic performance of this reaction system were investigated respectively and the experimental results were showed in Fig. 4.

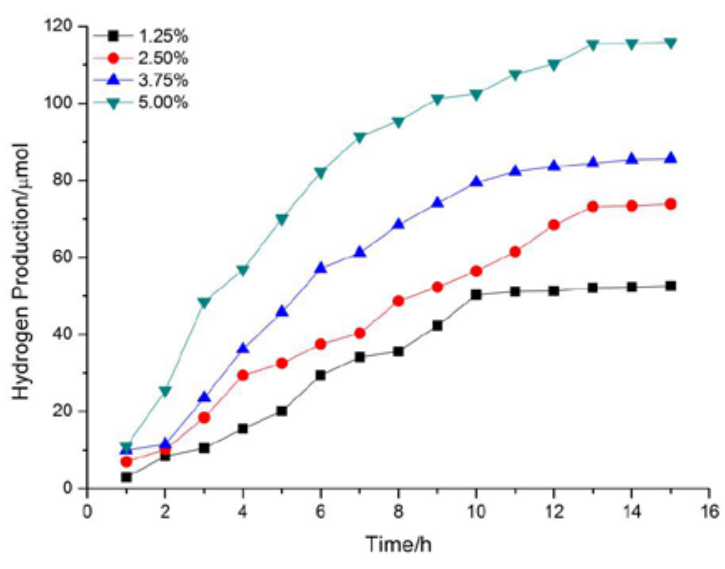

Fig. 4 Effects of electron donor concentrations on the performance of catalyst M for hydrogen production

Fig. 4 presented that the amounts of hydrogen production were increased gradually with the increasing of triethylamine contents from $1.25 \%$ to $5.00 \%$. When the triethylamine concentration was $5.00 \%$, catalyst $\mathrm{M}$ showed the best catalytic performance and hydrogen production was 115.9 $\mu \mathrm{mol}$. When the triethylamine concentration decreased to $1.25 \%$, the amount of hydrogen production was reduced to $48.9 \mu \mathrm{mol}$ after reacted for $15 \mathrm{~h}$. Therefore, the suitable triethylamine content was $5.00 \%$.

\subsection{Study on the Life of Catalyst System under Optimum Reaction Conditions}

The life of catalyst was investigated under the optimum reaction conditions and the results were showed in Fig. 5.

As shown in Fig. 5, the life of was $41 \mathrm{~h}$ under the optimal reaction conditions and the maximum hydrogen yield was $156.1 \mu \mathrm{mol}$ in the process of reaction. Fluorescein was added into the deactivated system and the reason of deactivation of catalyst was investigated. Results of Fig. 5 showed there was no hydrogen produced again which indicated that the proton reduction was mainly due to the loss of catalyst activity. 


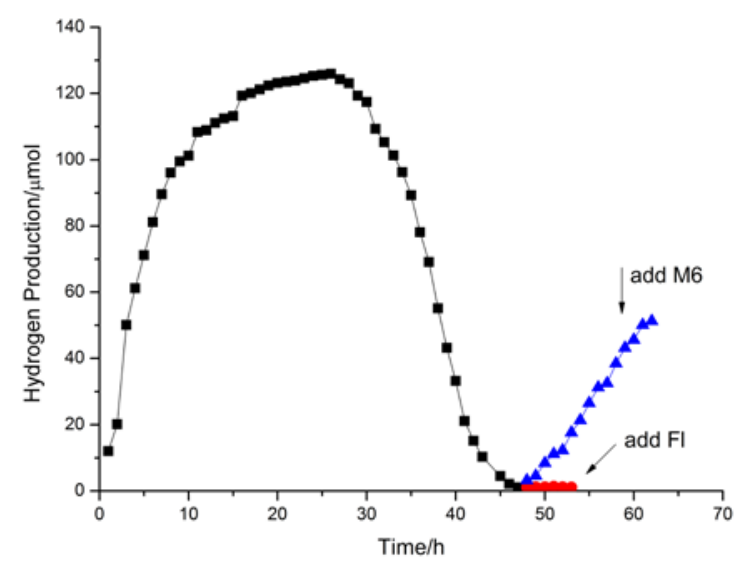

Fig. 5 Study on the life of catalyst under the optimum reaction conditions

\section{Conclusions}

Thiolate complexes Fe(phen)(pyS) $2(\mathrm{M})$ has been synthesized and the performances of complexes were studied. The results indicated Febalt thiolate complexes $\mathrm{M}$ are active for light-driven hydrogen production in aqueous/organic mixtures and the maximum hydrogen yield was $156.1 \mu \mathrm{mol} / \mathrm{h}$ after reacted for 15 hours and the life of catalyst $\mathrm{M}$ was $41 \mathrm{~h}$ under the optimal reaction conditions.

\section{Acknowledgments}

This work was supported by the National Natural Science Foundation of China (21106022), Science and Technology Planning Project of Guangdong Province, China (2013B010404045) and Educational Commission of Guangdong Province, China (Yq2013100).

\section{References}

[1] Service R F. Is it time to shoot for the sun.[J]. Science (Washington, D. C.), 2005, 309(5734): 548-551.

[2] Eisenberg R, Nocera D G. Preface: Overview of the forum on solar and renewable energy [J]. Inorganic chemistry, 2005, 44(20): 6799-6801.

[3] Lubitz W, Tumas W. Hydrogen: an overview [J]. Chemical reviews, 2007, 107(10): 3900-3903.

[4] Han S B, Kang T B, Joo O S, et al. Water splitting for hydrogen production with ferrites[J]. Solar Energy, 2007, 81(5): 623-628.

[5] Kudo A, Miseki Y. Heterogeneous photocatalyst materials for water splitting [J]. Chemical Society Reviews, 2009, 38(1): 253-278.

[6] Goldsmith J I, Hudson W R, Lowry M S, et al. Discovery and high-throughput screening of heteroleptic iridium complexes for photoinduced hydrogen production[J]. Journal of the American Chemical Society, 2005, 127(20): 7502-7510.

[7] Dong J, Wang M, Zhang P, et al. Promoting effect of electrostatic interaction between a cobalt catalyst and a xanthene dye on visible-light-driven electron transfer and hydrogen production[J]. The Journal of Physical Chemistry C, 2011, 115(30): 15089-15096. 